ISSN 0103-9954

\title{
MINIESTAQUIA DE Eucalyptus benthamii $\times$ Eucalyptus dunnii: ( I ) SOBREVIVÊNCIA DE MINICEPAS E PRODUÇÃO DE MINIESTACAS EM FUNÇÃO DAS COLETAS E ESTAÇÕES DO ANO
}

\author{
Eucalyptus benthamii × Eucalyptus dunnii MINICUTTING TECHNIQUE: ( I ) MINISTUMPS \\ SURVIVAL AND MINI-CUTTINGS PRODUCTION IN RELATION TO \\ COLLECTION AND SEASONS
}

\author{
Gilvano Ebling Brondani ${ }^{1}$ Ivar Wendling ${ }^{2}$ Fernando Grossi ${ }^{3}$ \\ Leonardo Ferreira Dutra ${ }^{4}$ Marla Alessandra Araujo ${ }^{5}$
}

\begin{abstract}
RESUMO
O trabalho teve como objetivo avaliar a técnica de miniestaquia na clonagem de Eucalyptus benthamii $\times$ Eucalyptus dunnii ao longo das estações do ano quanto à sobrevivência de minicepas e à produção de miniestacas. As minicepas dos clones H12, H19 e H20 foram manejadas durante 352 dias em minijardim clonal sob sistema semi-hidropônico em leito de areia com solução nutritiva fornecida por gotejamento, efetuando-se 27 coletas sucessivas de brotações durante as quatro estações do ano (primavera, verão, outono e inverno). O experimento foi conduzido no delineamento inteiramente casualizado contendo cinco repetições e quatro minicepas por repetição. As minicepas apresentaram elevado percentual de sobrevivência $(89,68 \%)$ após 27 coletas sucessivas de brotações, indicando alta longevidade como fontes fornecedoras de propágulos. A produção de miniestaca variou conforme o clone e mostrou-se sensível às estações do ano e às oscilações da temperatura. A maior produção ocorreu nas estações consideradas mais quentes (primavera e verão) com variação de 635,42 a 852,64 miniestacas $\mathrm{m}^{-2}$, e a menor nas estações mais frias (outono e inverno) com 592,38 a 629,36 miniestacas $\mathrm{m}^{-2}$. A produção anual de miniestacas foi de 18.934,76; 20.942,27 e 20.748, 14 miniestacas $\mathrm{m}^{-2}$ ano $^{-1}$, respectivamente para os clones H12, H19 e H20.
\end{abstract}

Palavras-chave: propagação vegetativa; clonagem; produção de brotos; sazonalidade.

\begin{abstract}
This study aimed to evaluate, throughout the seasons, the mini-cutting technique as cloning method for Eucalyptus benthamii $\times$ Eucalyptus dunnii hybrids regarding to the mini-stumps survival and to the minicuttings production. The ministumps of H12, H19 and H20 clones were cultivated during 352 days in a clonal mini-garden under semi-hydroponic system in a sand bed, where the nutritive solution was supplied by drip irrigation. During the experiment, 27 successive mini-cuttings samplings were performed in four seasons of the year: spring, summer, autumn and winter. The experiment was conducted under whole a randomized design with five replications and four mini-stumps per replication. After 27 successive mini-
\end{abstract}

1. Engenheiro Florestal, MSc., Setor de Ciências Agrárias, Centro de Ciências Florestais e da Madeira, Programa de Pós-graduação em Engenharia Florestal, Universidade Federal do Paraná, Av. Pref. Lothário Meissner, 900, Jardim Botânico, Campus III, CEP 80210-170, Curitiba (PR). Bolsista CNPQ. gebrondani@yahoo.com.br

2. Engenheiro Florestal, Dr., Pesquisador da Embrapa Florestas, Centro Nacional de Pesquisa de Florestas (EMBRAPA), Estrada da Ribeira, Km 111, Caixa Postal 319, CEP 83411-000, Colombo (PR). ivar@cnpf.embrapa.br

3. Engenheiro Florestal, Dr., Professor Adjunto do Centro de Ciências Florestais e da Madeira, Universidade Federal do Paraná, Av. Pref. Lothário Meissner, 900, Jardim Botânico, Campus III, CEP 80210-170, Curitiba (PR). f_grossi@ufpr.br

4. Engenheiro Agrônomo, Dr., Pesquisador do Centro de Pesquisa Agropecuária de Clima Temperado, EMBRAPA Clima Temperado, Rodovia BR 392, Km 78, Caixa Postal 403, CEP 96001-970, Pelotas (RS). leo@cpact.embrapa.br

5. Engenheira Agrônoma, MSc., Setor de Ciências Agrárias, Departamento de Solos e Engenharia Agrícola, Programa de Pós-graduação em Ciência do Solo, Universidade Federal do Paraná, Rua dos Funcionários, 1.540, Bairro Juvevê, CEP 80035-050, Curitiba (PR). Bolsista CNPQ. marla.agro@bol.com.br

Recebido para publicação em 25/03/2009 e aceito em 11/01/2011 
cuttings samplings, the mini-stumps presented high survival percentage $(89.68 \%)$, which indicated their high longevity as sprouts supply sources. The mini-cuttings production varied in function of the clone and presented a high sensitivity of seasons and temperature variations. The highest mini-cutting production occurred in warmer seasons (spring and summer), with 635.42 until 852.64 mini-cuttings $\mathrm{m}^{-2}$ variation, and the lowest in the cooler seasons (autumn and winter), with 592.38 until 629.36 mini-cuttings $\mathrm{m}^{-2}$ variation. The mini-cutting annual production was 18,934.76; 20,942.27 and 20,748.14 mini-cuttings $\mathrm{m}^{-2}$ year-1 $^{-1}$ for H12, H19 and H20 clones, respectively.

Keywords: vegetative propagation; cloning; sprouts production; seasonality.

\section{INTRODUÇÃO}

A miniestaquia pode ser considerada uma variação da estaquia convencional (macroestaquia), que consiste, basicamente, na utilização de brotações deplantas propagadas pelo processo demacroestaquia, ou mudas produzidas por sementes (ALFENAS et al., 2004). O surgimento dessa técnica de propagação vegetativa advém da microestaquia, a qual utiliza a microcepa (originada a partir da micropropagação) como fonte de propágulo vegetativo (microestaca) (XAVIER e COMÉRIO, 1996). Contudo, os aspectos técnicos, estruturais, operacionais e de custo limitaram a difusão comercial da microestaquia em relação à miniestaquia (XAVIER e WENDLING, 1998).

Atualmente, a miniestaquia constitui-se o método mais adotado pelas grandes empresas florestais brasileiras para a clonagem de espécies de Eucalyptus. Sua execução consiste na quebra da dominância apical pela poda da macroestaca enraizada, a qual emite novas brotações (miniestacas) e estas são utilizadas para o enraizamento e formação de novas mudas, variável em função da época do ano, condições estruturais, clone/espécie e condições nutricionais (XAVIER e WENDLING, 1998; ALFENAS et al., 2004).

Como principais avanços, essa técnica promoveu a redução das dimensões do jardim clonal, que passou a ser chamado de minijardim clonal. Ele pode ser implantado em sistema de recipientes, que variam desde vasos de polipropileno de diferentes volumes, caixas de fibra de vidro com variadas formas e dimensões, ou em sistemas de "canaletões" de fibrocimento, atualmente o mais utilizado pelas grandes empresas florestais (HIGASHI et al., 2002).

Efeitos inerentes às condições ambientais, como temperatura, fotoperíodo e luminosidade, condicionados pela sazonalidade em cada região (ELDRIDGE et al., 1994; HARTMANN et al., 2002), a constituição genética do material a ser propagado (TITON et al., 2003b; WENDLING et al., 2003; FERREIRA et al., 2004; SOUZA JUNIOR et al., 2008), assim como fatores relacionados à idade ontogenética (WENDLING e XAVIER, 2001), influenciam significativamente a variação da produção de miniestacas.

Inúmeros trabalhos relacionados à propagação vegetativa de espécies de Eucalyptus, via técnica de miniestaquia, têm sido realizados com Eucalyptus dunnii (SOUZAJUNIOR e WENDLING, 2003; ROSA, 2006), Eucalyptus benthamii (CUNHA et al., 2005), Eucalyptus grandis (TITON et al., 2003a; SANTOS et al., 2005; WENDLING e XAVIER, 2005), Eucalyptus cloeziana (ALMEIDA et al., 2007) e outras espécies de Eucalyptus (WENDLING et al., 2000; WENDLING e XAVIER, 2003; FERREIRA et al., 2004; CUNHA, 2006).

Devido a inexistência de estudos sobre a propagação vegetativa de E. benthamii x E. dunnii, via técnica de miniestaquia, o trabalho teve como objetivo avaliar a sobrevivência de minicepas e a produção de miniestacas ao longo de sucessivas coletas nas estações da primavera, verão, outono e inverno.

\section{MATERIAL E MÉTODOS}

\section{Caracterização geral do experimento}

O trabalho foi conduzido de outubro de 2006 a setembro de 2007, no Laboratório de Propagação de Plantas da Embrapa Florestas - CNPF, situada em Colombo - PR (25²0' S e 49¹4' W, 950 m). Segundo classificação de Köppen, o clima da região é temperado, do tipo $\mathrm{Cfb}$.

\section{Obtenção dos clones e constituição do minijardim clonal}

Utilizaram-se genótipos superiores do híbrido natural de Eucalyptus benthamii $\times$ Eucalyptus dunnii de 12 meses de idade, identificados como H12, H19 e H20. As matrizes foram plantadas no município de Guarapuava - PR no espaçamento de $3 \mathrm{~m}$ x $2 \mathrm{~m}$. A partir das brotações produzidas pelas

Ci. F1., v. 22, n. 1, jan.-mar., 2012 
matrizes decepadas foram obtidas estacas dos ramos da parte aérea, as quais foram enraizadas em casa de vegetação. Como recipientes de cultivo foram utilizados tubetes plásticos de forma cônica de $55 \mathrm{~cm}^{3}$, contendo, como substrato, a mistura de casca de arroz carbonizada, vermiculita média e substrato comercial a base de casca de pinus e vermiculita $(1: 1: 1 \mathrm{v} / \mathrm{v})$. Em Janeiro de 2006, mudas dos clones, com 90 dias de idade e com $15 \mathrm{~cm}$ de altura, foram transferidas para sistema semi-hidropônico de canaletão em leito de areia e plantadas no espaçamento $10 \mathrm{~cm}$ x $15 \mathrm{~cm}$.

Decorridos 21 dias para adaptação das mudas ao sistema semi-hidropônico, procedeu-se a poda da brotação apical para formar as minicepas. A poda foi efetuada $7 \mathrm{~cm}$ acima do caule da brotação de cada estaca enraizada, tomando-se o cuidado de manter, no mínimo, um par de folhas remanescentes por minicepa, conforme Brondani (2008).

\section{Manejo e nutrição das minicepas}

O minijardim clonal foi mantido em condições de estufa não climatizada e recoberta com polietileno, onde as minicepas foram submetidas a sucessivas coletas de brotações produzidas durante todo o período experimental.

As minicepas receberam solução nutritiva por gotejamento 3 vezes ao dia a uma vazão total de $5 \mathrm{~L} \mathrm{~m}^{-2}$. A solução nutritiva foi composta por monoamônio fosfato $\left(0,04 \mathrm{~g} \mathrm{~L}^{-1}\right)$, sulfato de magnésio $\left(0,40 \mathrm{~g} \mathrm{~L}^{-1}\right)$, nitrato de potássio $(0,44 \mathrm{~g}$ $\left.\mathrm{L}^{-1}\right)$, sulfato de amônio $\left(0,31 \mathrm{~g} \mathrm{~L}^{-1}\right)$, cloreto de cálcio $\left(0,79 \mathrm{~g} \mathrm{~L}^{-1}\right)$, ácido bórico $\left(2,88 \mathrm{mg} \mathrm{L}^{-1}\right)$, sulfato de manganês $\left(3,70 \mathrm{mg} \mathrm{L}^{-1}\right)$, molibdato de sódio $(0,18$ $\left.\mathrm{mg} \mathrm{L}^{-1}\right)$, sulfato de zinco $\left(0,74 \mathrm{mg} \mathrm{L}^{-1}\right)$ e hidroferro em pó $\left(81,80 \mathrm{mg} \mathrm{L}^{-1}\right)$, o qual possuía $6 \%$ de $\mathrm{Fe}$ em sua composição. A solução nutritiva foi substituída a cada três semanas, sendo a condutividade elétrica mantida em $1,6 \mathrm{mS} \mathrm{m}^{-2}$ a $25^{\circ} \mathrm{C}$ e o $\mathrm{pH}$ ajustado a $5,5( \pm 0,1)$. A análise química da água apresentou as seguintes características: $1,4 \mathrm{mg} \mathrm{L}^{-1}$ de $\mathrm{N}_{-\mathrm{NO}_{3}, 0,4}$

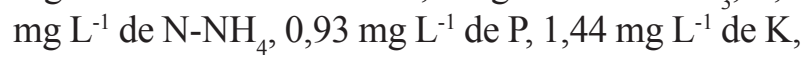
26,08 $\mathrm{mg} \mathrm{L}^{-1}$ de Ca, 5,07 $\mathrm{mg} \mathrm{L}^{-1}$ de $\mathrm{Mg}^{4}$, 0,4 mg L $\mathrm{mg}^{-1}$ de $\mathrm{Cu}, 0,09 \mathrm{mg} \mathrm{L}^{-1}$ de Fe, 0,04 mg L $\mathrm{m}^{-1}$ de Mn e 0,04 mg $\mathrm{L}^{-1}$ de $\mathrm{Zn}$.

\section{Coleta de brotações}

As coletas foram efetuadas em diferentes intervalos de tempo e de maneira seletiva, ou seja, brotações menores que $5 \mathrm{~cm}$ e com menos de 3 pares de folhas foram mantidas na minicepa para as coletas subsequentes. Em função da época do ano, o intervalo entre cada coleta variou de 8 a 21 dias, mantendo-se a padronização estabelecida quanto à seleção das brotações.

\section{Avaliação da sobrevivência de minicepas e produção de miniestacas}

A sobrevivência das minicepas e a produção de miniestacas do minijardim clonal foram avaliadas durante o período de 12 meses (outubro de 2006 a setembro de 2007) efetuando-se 27 coletas sucessivas, contemplando as 4 estações do ano (primavera, verão, outono e inverno). $\mathrm{O}$ experimento foi instalado 7 meses após o plantio das mudas no sistema semi-hidropônico. Além da análise dos dados em função das diferentes coletas, também foi possível avaliar os efeitos das estações do ano sobre as coletas. Para tanto, utilizaram-se os valores médios dentro de cada estação para comparar a variação da produção dos clones (H12, H19 e H20) ao longo da primavera (22 de setembro a 21 de dezembro), verão ( 22 de dezembro a 21 de março), outono (22 de março a 21 de junho) e inverno ( 22 de junho a 21 de setembro).

Como variáveis, foram mensuradas as características da sobrevivência de minicepas (SM), produção de miniestacas por metro quadrado (PMQ) e a produção de miniestacas por metro quadrado ao ano (PMQA).

O experimento da sobrevivência de minicepas e produção de miniestacas, em função das coletas, foi conduzido no delineamento inteiramente casualizado em arranjo fatorial (3x27), sendo os fatores constituídos por três clones (H12, H19 e H20) e 27 coletas sucessivas de brotações ao longo de 352 dias. Para a produção de miniestacas em função das estações do ano, o experimento foi conduzido no delineamento inteiramente casualizado em arranjo fatorial $(3 \times 4)$, sendo os fatores constituídos por três clones (H12, H19 e H20) e quatro estações do ano (primavera, verão, outono e inverno). Nos dois experimentos foram utilizadas cinco repetições, contendo quatro minicepas por repetição.

\section{Procedimentos estatísticos}

Os dados foram submetidos ao teste de Bartlett $(p<0,05)$, a fim de verificar a homogeneidade da variância entre os tratamentos e, em seguida, procedeu-se a análise de variância (ANOVA) $(p<0,01$ e $p<0,05)$ e a correlação de Pearson $(p<0,01$ e $p<0,05)$ entre as características amostradas. Os dados foram comparados pelo teste de Tukey $(p<0,05)$. Utilizou-se o pacote estatístico SOC (EMBRAPA, 1990). 


\section{RESULTADOS E DISCUSSÃO}

\section{Sobrevivência de minicepas}

Houve interação $(p<0,01)$ entre os fatores testados quanto à produção de miniestaca por metro quadrado (PMQ). No entanto, a sobrevivência das minicepas (SM) apenas variou significativamente $(p<0,01)$ quanto ao fator clone, não existindo efeito das coletas (Tabela 1).

$\mathrm{O}$ melhor desempenho quanto à SM ocorreu para o clone $\mathrm{H} 20$, que apresentou $100 \%$ de sobrevivência de minicepas durante os 352 dias de coletas sucessivas de miniestacas, diferindo significativamente dos demais. $\mathrm{O}$ clone H12 apresentou valor médio de $91,82 \%$ de SM, desempenhando comportamento intermediário para essa característica. A maior mortalidade observada de minicepas foi verificada para o clone H19, o qual apresentou $77,22 \%$ de SM, o que leva a supor, maior sensibilidade desse clone quanto aos efeitos do manejo e condições ambientais no minijardim clonal (Figura 1). A mortalidade de minicepas do clone H19 começou a ser registrada a partir da $6^{\mathrm{a}}$ coleta de brotações, sendo que para o clone H12 iniciou a partir da $7^{\mathrm{a}}$ coleta.

TABELA 1: Resumo da análise de variância para a sobrevivência das minicepas (SM) e produção de miniestaca por metro quadrado (PMQ) de Eucalyptus benthamii $\times$ Eucalyptus dunnii.

TABLE 1: Variance analysis summary for ministumps survival (SM) and mini-cutting production per square meter (PMQ) of Eucalyptus benthamii $\times$ Eucalyptus dunnii.

\begin{tabular}{lccc}
\hline \multirow{2}{*}{$\begin{array}{c}\text { Causas da } \\
\text { Variação }\end{array}$} & GL & \multicolumn{2}{c}{ Quadrados Médios } \\
\cline { 3 - 4 } Clone (CL) & 2 & $16.918,20 * *$ & $145.849,70 * *$ \\
Coleta (COL) & 26 & $121,55^{\text {ns }}$ & $367.876,23 * *$ \\
CL x COL & 52 & $43,20{ }^{\mathrm{ns}}$ & $52.975,74 * *$ \\
Resíduo & 324 & 243,05 & $9.216,03$ \\
Média & - & 89,68 & 688,23 \\
CV $_{\text {exp. }}(\%)$ & - & 17,30 & 13,95 \\
\hline
\end{tabular}

Em que: ${ }^{\text {ns }}=$ não significativo a $5 \%$ de probabilidade de erro, pelo teste $\mathrm{F} ; * *=$ significativo a $1 \%$ de probabilidade de erro, pelo teste F; GL = graus de liberdade, $\mathrm{CV}_{\text {exp. }}=$ coeficiente de variação experimental; minies. = miniestaca.

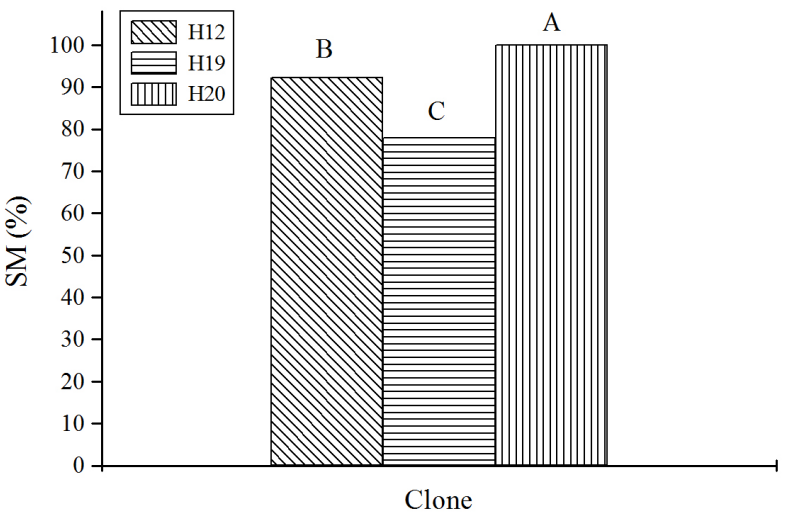

FIGURA 1: Valores médios da sobrevivência de minicepas (SM) dos clones H12, $\mathrm{H} 19$ e $\mathrm{H} 20$ de Eucalyptus benthamii $\times$ Eucalyptus dunnii, ao longo de 352 dias de coletas sucessivas de miniestacas. Médias diferem significativamente pelo teste de Tukey a $5 \%$ de probabilidade de erro.

FIGURE 1: Mean values for mini-stump survival (SM) of Eucalyptus benthamii $\times$ Eucalyptus dunnii $\mathrm{H} 12, \mathrm{H} 19$ and $\mathrm{H} 20$ clones, in 352 days of mini-cutting successive collections. Averages differ significantly by Tukey test at $5 \%$ of error probability.

Segundo Hartmann et al. (2002) cada material genético pode responder de maneira diferenciada à propagação vegetativa. Esse fato foi confirmado no presente estudo, onde os três clones estudados apresentaram comportamento diferenciado quanto à sobrevivência de minicepas (SM), ao longo das 27 coletas efetuadas.

Estudos realizados por Wendling (1999) indicaram alta sobrevivência de minicepas de Eucalyptus spp. para todos os clones estudados, com valores médios superiores a $95 \%$ após cinco coletas de miniestacas. Titon et al. (2003b) também relataram sobrevivência de minicepas superior a 98\% para Eucalyptus grandis, após 8 coletas. Em outro estudo, Wendling et al. (2003) observaram sobrevivência de minicepas de Eucalyptus grandis superior a $96 \%$ após 7 coletas de miniestacas, independente do clone e subcultivo estudados.

Souza Junior e Wendling (2003), ao trabalharem com Eucalyptus dunnii, observaram $100 \%$ de sobrevivência de minicepas após quatro coletas de miniestacas. Resultados similares foram encontrados por Rosa (2006), que relatou 
sobrevivência de minicepas em torno de $100 \%$, após 14 coletas de brotações de Eucalyptus dunnii. Cunha et al. (2005) relataram $88 \%$ de sobrevivência de minicepas de Eucalyptus benthamii, após cinco coletas de miniestacas.

Os valores médios de sobrevivência apresentados pelos clones $\mathrm{H} 20$ e H12 corroboram com os existentes na literatura, embora aqueles reportem um número bastante inferior de coletas de miniestacas, em comparação com as 27 coletas efetuadas no presente estudo. Dessa forma, mesmo que o clone H19 tenha apresentado a menor sobrevivência em relação aos demais, isto não inviabiliza a sua condução para a produção de brotações, pois os clones não apresentaram mortalidade elevada de minicepas durante os 352 dias (Figura 1). Além disso, deve-se considerar o maior desenvolvimento das raízes ao longo das sucessivas coletas de brotações, o que proporciona maior aporte de nutrientes e, consequentemente, influencia a qualidade da minicepa e brotação emitida.

Com base nessas observações e, nas condições deste experimento, pode-se inferir que as minicepas apresentam longevidade satisfatória para a produção de miniestacas, o que possibilitou inúmeras coletas sucessivas de brotações sem a ocorrência de mortalidade significativa das mesmas, em relação ao fator coleta de brotações (Tabela 1), não sendo necessária a sua substituição em um curto espaço de tempo. Em termos gerais, a alta sobrevivência das minicepas evidencia que a metodologia adotada ao longo do período experimental, quanto às condições de cultivo no minijardim clonal, foram tecnicamente adequadas.

\section{Produção de miniestacas em função das coletas}

$\mathrm{O}$ valor do $\mathrm{CV}_{\text {exp. }}$ obtido para a PMQ está condizente com os registrados na literatura para miniestaquia de Eucalyptus (WENDLING, 1999; TITON et al., 2003b), o que denota adequada precisão experimental (Tabela 1).

Os menores intervalos entre as coletas de brotações ocorreram durante as estações da primavera, de 9 a 11 dias, e verão, de 8 a 15 dias, proporcionando as maiores quantidades de coleta de propágulos. Na primavera foi possível realizar um total de 9 coletas e no verão um total de 7 coletas (Figura 2). Nas estações do outono e inverno, as quais correspondem aos períodos de repouso vegetativo, verificou-se queda do número de coletas de brotações, apresentando valores de 5 e 6 coletas, respectivamente. Nesses períodos, os intervalos entre as coletas foram maiores, variando de 14 a 18 dias no outono e, de 14 a 21 dias durante o inverno (Figura 2).

Na estação da primavera, a PMQ do clone H12 apresentou variação de 556,00 a 792,98 miniestacas $\mathrm{m}^{-2}$ por coleta. Já a produção para o clone H19 variou de 548,00 a 918,75 miniestacas $\mathrm{m}^{-2} \mathrm{e}$, o clone H20 apresentou produção de 399,58 a 1.040,67 miniestacas $\mathrm{m}^{-2}$ (Figura 2a). No verão o clone H12 apresentou variação de 583,33 a 848,75 miniestacas $\mathrm{m}^{-2}$, o clone $\mathrm{H} 19$ variou de 616,39 a $1.050,97$ miniestacas $\mathrm{m}^{-2}$ e o clone $\mathrm{H} 20$ de 283,33 a 1.005,67 miniestacas $\mathrm{m}^{-2}$ (Figura 2b). No outono foi registrada variação da produção de 309,17 a 926,52 miniestacas $\mathrm{m}^{-2}$ para o clone $\mathrm{H} 12$, de 370,42 a 770,36 miniestacas $\mathrm{m}^{-2}$ para o clone $\mathrm{H} 19$ e de 323,75 a 759,00 miniestacas $\mathrm{m}^{-2}$ para o clone H20 (Figura 2c). Durante o inverno o clone H12 apresentou variação de 391,03 a 951,61 miniestacas $\mathrm{m}^{-2}$, o clone H19 apresentou variação da produção de 490,07 a 1.015,55 miniestacas $\mathrm{m}^{-2}$ e o clone H20 variação de 291,67 a 847,08 miniestacas $\mathrm{m}^{-2}$ (Figura 2d).

A PMQ (Figura 2) apresentou oscilação ao longo das 27 coletas efetuadas. Tal fato concorda com os resultados registrados na literatura ao empregar a técnica de miniestaquia para espécies de Eucalyptus (WENDLING, 1999; SOUZA JUNIOR e WENDLING, 2003; TITON et al., 2003b; WENDLING et al., 2003; CUNHA et al., 2005; ROSA, 2006), onde o efeito de alta produção de brotações seguido de queda e novamente sucedida por uma alta produtividade é frequente. Esses efeitos podem estar relacionados ao vigor fisiológico das minicepas (WENDLING, 1999; HIGASHI et al., 2002; ROSA, 2006), onde o balanço nutricional da minicepa e a retomada ao crescimento de novas brotações, fatores que variam em função da frequente coleta de miniestacas, desempenham papel fundamental para desencadear esse tipo de comportamento. Titon et al. (2003b) salientam que o efeito cíclico da produção de brotações deve estar associado, também, aos clones (genótipos) e ao manejo adotado na fertirrigação, cuja nutrição equilibrada permite o desenvolvimento mais vigoroso das brotações. Além disso, fatores ligados à variação da temperatura, à juvenilidade das minicepas e à sazonalidade (WENDLING et al., 2003; ALFENAS et al., 2004) também podem afetar significativamente a produção de miniestacas, bem como, o intervalo entre as coletas. 

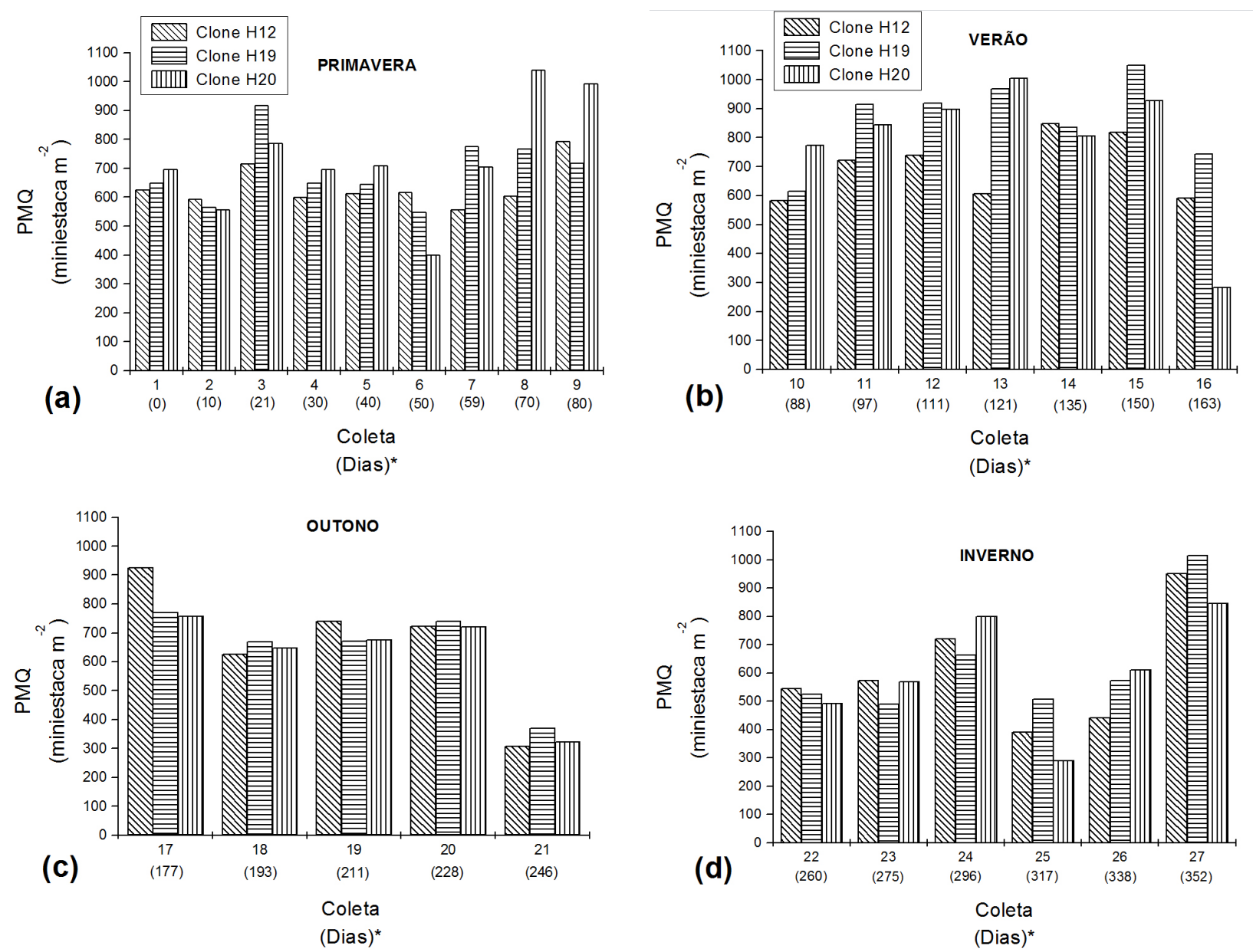

FIGURA 2: Variação da produção de miniestacas por metro quadrado (PMQ) de Eucalyptus benthamii $\times$ Eucalyptus dunnii, ao longo de 352 dias de coletas sucessivas de miniestacas, em sistema semi-hidropônico com substrato de areia. (a): coleta de miniestacas na estação da primavera, (b): verão, (c): outono e (d): inverno. * Valores entre parênteses referem-se ao intervalo de dias entre as coletas.

FIGURE 2: Mini-cuttings production variation per square meter (PMQ) of Eucalyptus benthamii $\times$ Eucalyptus dunnii, in 352 days of mini-cuttings successive collection in semi-hydroponic system with sand substratum. (a): mini-cuttings collection in spring, (b) summer, (c): autumn and (d) winter. * Values in parentheses refer to the interval of days between collections.

Rosa (2006), embora tenha registrado menores índices de produção, também verificou distribuição desigual das coletas de brotações na miniestaquia de Eucalyptus dunnii nas quatro estações do ano. No entanto, o autor trabalhou com sistema de produção em minijardim clonal do tipo tubete, o que geralmente apresenta menor produção de miniestacas em comparação ao sistema semi-hidropônico, o qual pode apresentar o dobro ou mais de produção (CUNHA et al., 2005; CUNHA, 2006). Segundo Assis e Mafia (2007), a maior produtividade de miniestacas em leito de areia, provavelmente, deve estar relacionada com o maior volume de substrato passível de exploração pelo sistema radicial da minicepa, e dessa forma, alcançar maior estabilidade nutricional.

A ANOVA revelou efeito significativo $(p<0,01)$ para a produção de miniestacas por metro quadrado ao ano (PMQA), em função do fator clone (Tabela 2).

Os clones H19 e H20 não diferiram significativamente quanto à produção de miniestacas por metro quadrado ao ano (PMQA), apresentando valores médios de 20.942,27 miniestacas $\mathrm{m}^{-2}$ ano $^{-1}$ e 20.748,14 miniestacas $\mathrm{m}^{-2}$ ano $^{-1}$, respectivamente. Porém, diferiram do clone H12, o qual apresentou a menor média para essa característica, com 18.934,76 miniestacas $\mathrm{m}^{-2}$ ano $^{-1}$ (Figura 3 ). 
TABELA 2: Resumo da análise de variância para a produção de miniestaca por metro quadrado ao ano (PMQA) de Eucalyptus benthamii $\times$ Eucalyptus dunnii.

TABLE 2: Variance analysis summary for minicutting production per square meter year (PMQA) of Eucalyptus benthamii $\times$ Eucalyptus dunnii.

\begin{tabular}{|c|c|c|}
\hline \multirow{2}{*}{$\begin{array}{c}\text { Causas da } \\
\text { Variaçãao }\end{array}$} & \multirow{2}{*}{ GL } & Quadrados Médios \\
\hline & & PMQA (minies. $\mathrm{m}^{-2}$ ano $^{-1}$ ) \\
\hline Clone (CL) & 2 & $6.130 .100,69 * *$ \\
\hline Resíduo & 12 & $769.052,73$ \\
\hline Média & - & $20.208,39$ \\
\hline $\mathrm{CV}_{\text {exp. }}(\%)$ & - & 4,34 \\
\hline
\end{tabular}

Em que: $* *=$ significativo a $1 \%$ de probabilidade de erro, pelo teste $\mathrm{F} ; \mathrm{GL}=$ graus de liberdade; $\mathrm{CV}_{\text {exp. }}=$ coeficiente de variação experimental; minies. $=$ miniestaca.

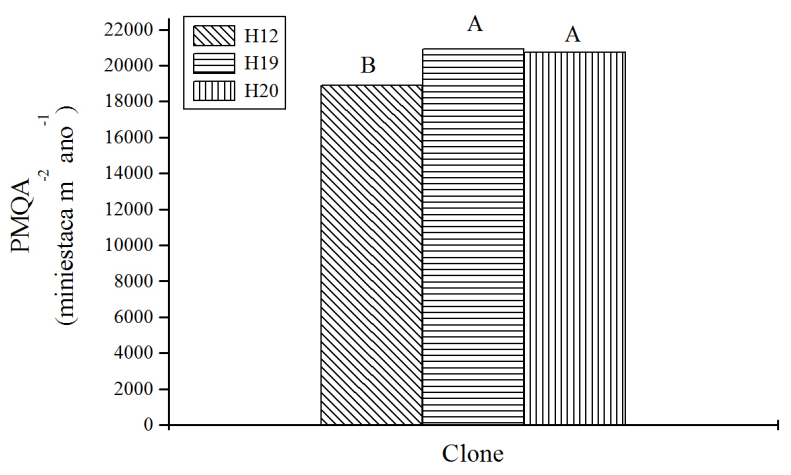

FIGURA 3: Valores médios da produção de miniestacas por metro quadrado ao ano (PMQA) de dos clones H12, H19 e H20 de Eucalyptus benthamii $\times$ Eucalyptus dunnii, ao longo de 352 dias de coletas sucessivas de miniestacas, em sistema semi-hidropônico com substrato de areia. Médias seguidas por mesma letra não diferem significativamente pelo teste de Tukey a $5 \%$ de probabilidade de erro.

FIGURE 3: Mean values for mini-cutting production per square meter year (PMQA) of Eucalyptus benthamii $\times$ Eucalyptus dunnii H12, H19 and H20 clones, in 352 days of minicutting successive collections in semi-hydroponic system with sand substratum. Averages followed by same letter do not differ significantly by Tukey test at $5 \%$ of error probability.
Os dados apresentados para a característica da PMQA encontram-se dentro dos padrões registrados na literatura para espécies de Eucalyptus, quando se utiliza miniestaca apical como propágulo e oriundos de minicepas manejadas em minijardim clonal. Geralmente, esse tipo de sistema de produção apresenta variação de 7.488 a 41.480 miniestacas $\mathrm{m}^{-2}$ $\mathrm{ano}^{-1}$, dependendo do tipo de minijardim clonal e do material genético (ALFENAS et al., 2004).

Em termos gerais, as minicepas não apresentaram tendência de exaustão definitiva em função de cada estação, mas sim temporária. Esse fato pode ser evidenciado pelo aumento dos valores da PMQ ocorridos na $27^{\mathrm{a}}$ coleta (entrada da primavera), em que os índices de produção chegaram próximos aos valores registrados durante a primavera, independente da característica mensurada. Portanto, a queda ou aumento da produção de miniestacas ocorridos dentro do período experimental estariam mais ligados, possivelmente, a fatores ambientais como a variação da temperatura e luminosidade, condicionadas pela sazonalidade, e ao manejo adotado, como o intervalo e a intensidade de poda, visto que, a nutrição fornecida às minicepas e o tipo de poda foram os mesmos ao longo das quatro estações.

Segundo Titon et al. (2003b) o comportamento cíclico referente à produção de propágulos vegetativos pode estar associado a um princípio de exaustão temporária das minicepas. Devido a essa característica, pode-se supor que, caso fosse dado continuidade ao experimento, os resultados de produção poderiam ser semelhantes aos encontrados nas estações antecedentes e começariam a diminuir no instante em que as minicepas expressassem princípios de exaustão mais significativos, como a queda demasiada da produção de miniestacas e a perda do vigor, o que indicaria o momento da substituição por novas minicepas.

\section{Produção de miniestacas em função das estações do ano}

Houve interação quanto à variação da produção de miniestacas dos clones (H12, H19 e H20) em função das estações do ano (primavera, verão, outono e inverno) para as características da PMQ $(p<0,05)$ (Tabela 3).

Os valores do $\mathrm{CV}_{\text {exp. }}$ para a PMQ (Tabela 3) estão abaixo dos registrados na literatura para miniestaquia de espécies de Eucalyptus (WENDLING, 1999; TITON et al., 2003b), o que denota adequada precisão experimental. 
TABELA 3: Resumo da análise de variância para a produção de miniestaca por metro quadrado (PMQ) de Eucalyptus benthamii $\times$ Eucalyptus dunnii.

TABLE 3: Variance analysis summary for production minicuttings per square meter (PMQ) of Eucalyptus benthamii $\times$ Eucalyptus dunnii.

\begin{tabular}{lcc}
\hline \multirow{2}{*}{$\begin{array}{c}\text { Causas da } \\
\text { Variação }\end{array}$} & GL & Quadrados Médios \\
\cline { 3 - 3 } Clone (CL) & 2 & PMQ (minies. m $\left.^{-2}\right)$ \\
Estação (EST) & 3 & $113.367,0 * *$ \\
CL x EST & 6 & $5.665,8 *$ \\
Resíduo & 48 & $1.937,0$ \\
Média & - & 672,71 \\
CV & - & 6,54 \\
\hline
\end{tabular}

Em que: $*$ e $* *=$ significativo a $5 \%$ e $1 \%$ de probabilidade de erro, respectivamente, pelo teste $\mathrm{F} ; \mathrm{GL}=$ graus de liberdade; $\mathrm{CV}_{\text {exp. }}=$ coeficiente de variação experimental; minies. $=$ miniestaca.
O valor médio da produção de miniestacas por metro quadrado (PMQ) para o clone H20 foi 732,1 miniestacas $\mathrm{m}^{-2}$ na estação da primavera, diferindo significativamente do H12 (635,42 miniestacas $\mathrm{m}^{-2}$ ). $\mathrm{O}$ valor para o clone $\mathrm{H} 19$ não diferiu dos demais, com valor médio de 692,92 miniestacas $\mathrm{m}^{-2}$. Durante o verão, novamente ocorreu diferença do comportamento entre os clones. Nessa estação o $\mathrm{H} 19$ apresentou 852,64 miniestacas $\mathrm{m}^{-2}$, diferindo do H12, o qual correspondeu a uma PMQ de 729,84. O clone H20 não diferiu significativamente dos demais, resultando em valor médio de 787,88 miniestacas $\mathrm{m}^{-2}$. Durante o outono, o H12 apresentou 600,48 miniestacas $\mathrm{m}^{-2}$; o H19 apresentou 612,86 miniestacas $\mathrm{m}^{-2}$ e o H20 valor médio de 592,38 miniestacas $\mathrm{m}^{-2}$. No inverno os valores da PMQ foram de 604,22, 629,36 e 602,48 miniestacas $\mathrm{m}^{-2}$, respectivamente para os clones H12, H19 e H20 (Figura 4).

Ao se comparar a variação da PMQ do clone H12, entre as estações do ano, verifica-se que não existiu diferença entre a primavera e o verão, no entanto, a PMQ durante o verão diferiu com as

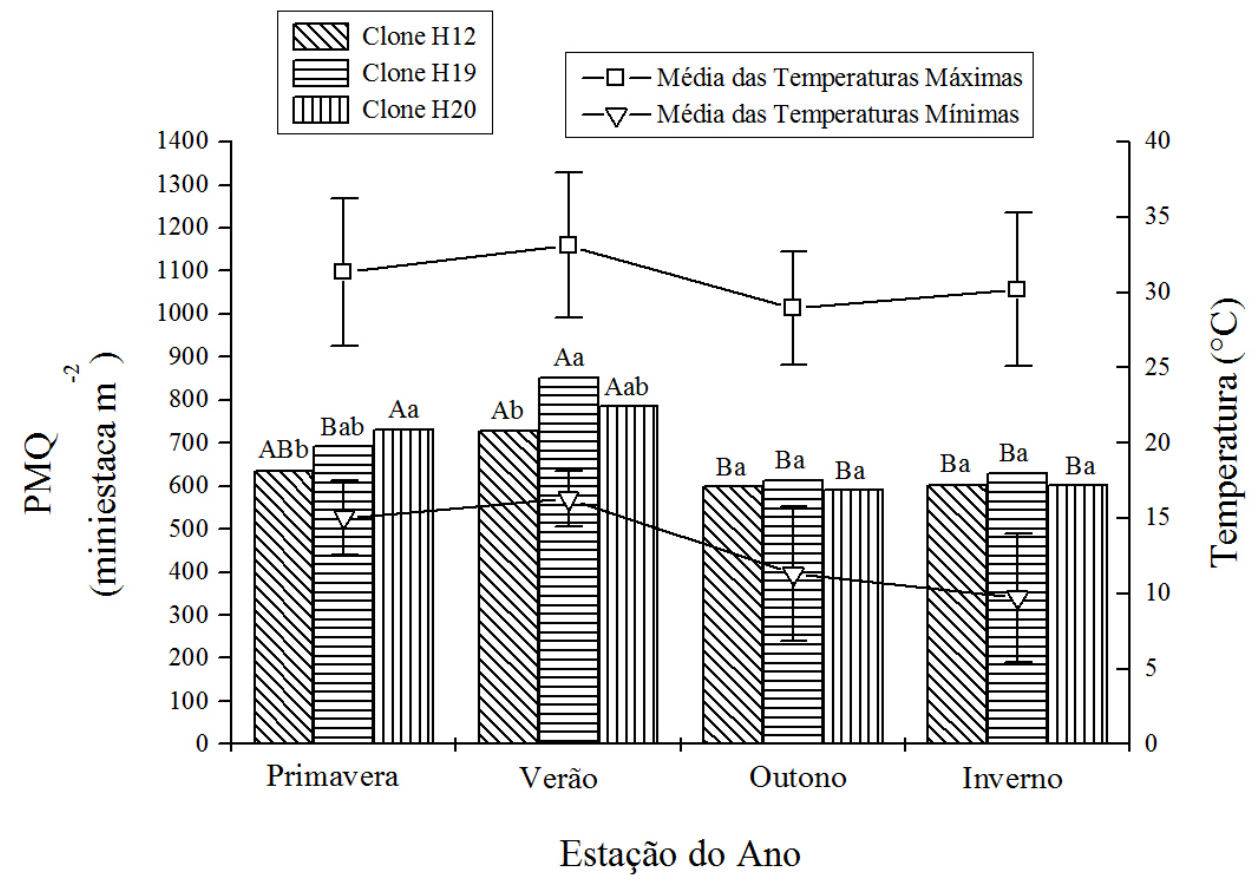

FIGURA 4: Valores médios da produção de miniestacas por metro quadrado (PMQ) dos clones H12, H19 e H20 de Eucalyptus benthamii $\times$ Eucalyptus dunnii em função da estação do ano. Médias seguidas por mesma letra maiúscula para o mesmo clone entre as diferentes estações do ano e letras minúsculas entre os clones dentro da mesma estação do ano não diferem significativamente pelo teste de Tukey a 5\% de probabilidade de erro.

FIGURE 4: Mean values for minicuttings production per square meter (PMQ) of Eucalyptus benthamii $\times$ Eucalyptus dunnii $\mathrm{H} 12$, $\mathrm{H} 19$ and $\mathrm{H} 20$ clones, in according to the seasons. Averages followed by same capital letter for the same clone between different seasons of the year and lowercase letters between the clones in the same season of the year do not differ significantly by Tukey test at $5 \%$ of error probability. 
registradas no outono e inverno. O clone $\mathrm{H} 20$ não apresentou diferença da PMQ na primavera e verão, porém, ambas as estações diferiram dos valores registrados durante o outono e inverno. O H19 foi o único clone que apresentou o máximo valor de PMQ durante o verão, diferindo, significativamente, das demais estações do ano (Figura 4).

Segundo Eldridge et al. (1994) e Alfenas et al. (2004) a coleta seletiva e contínua de propágulos, para o enraizamento, depende muito da temperatura, intensidade luminosa e fotoperíodo nas diferentes estações do ano, as quais são pronunciadas especialmente em regiões subtropicais, como no sul do Brasil. Possivelmente, esses fatores podem ter sido determinantes para os resultados obtidos no presente estudo, pois em termos gerais, fica evidente que a produção de miniestacas acompanhou a variação da temperatura ao longo das estações do ano (Figura 4).

A PMQ mostrou correlação significativa com a variação da média das temperaturas máximas (Tmáx), temperaturas médias (Tméd) e temperaturas mínimas (Tmín) registradas na estufa de polietileno (Tabela 4). Esse fato indica alta sensibilidade dessa característica às variações térmicas, influenciando significativamente o padrão de comportamento da produção de miniestacas. Contudo, devem-se considerar outros fatores como o fotoperíodo e intensidade luminosa, os quais não foram monitorados no presente estudo.

Pode-se verificar que os maiores valores da PMQ (Figura 4) foram registrados durante a primavera e o verão, com redução nas estações de outono e inverno, as quais foram acompanhadas pela demasiada queda das médias das temperaturas máximas, principalmente, das mínimas. Resultados semelhantes foram registrados por Rosa (2006) que verificou, a partir da $9^{\mathrm{a}}$ coleta de brotações, decréscimo do número de miniestacas de Eucalyptus dunnii produzidas ao dia com a redução dos valores médios das temperaturas máximas e mínimas, independente do tratamento testado. Estudos desenvolvidos por Cunha (2006) reforçam que as condições meteorológicas condicionam significativamente a produção de miniestacas por minicepa. Em seus trabalhos, o autor observou que o aumento da temperatura no leito de cultivo, ocasionado pela época do ano, favoreceu positivamente a produção de miniestacas, independente do tipo de minijardim clonal (leito de areia ou tubete).

$\mathrm{Na}$ miniestaquia de espécies de Eucalyptus a produção de brotações varia muito conforme as condições de trabalho. Cunha et al. (2005) observaram produção média de 8,1 miniestacas por minicepa ao estudar a propagação vegetativa de Eucalyptus benthamii em sistema de canaletão, com intervalos entre coletas variando de 25 a 30 dias. Em outro estudo, Souza Junior e Wendling (2003) observaram variação de 1,7 a 2,6 miniestacas por minicepa nas primeiras coletas de propágulos efetuadas para Eucalyptus dunnii. Titon et al. (2003b) observaram valor médio de 9,7 miniestacas por minicepa para quatro clones de Eucalyptus grandis, dentro de oito coletas efetuadas, sendo superior à produção de miniestacas ao comparar com a microestaquia, que foi de 8,5 por microcepa.

TABELA 4: Matriz de Correlação de Pearson entre a sobrevivência de minicepas (SM), produção de miniestacas por metro quadrado (PMQ), médias das temperaturas máximas (Tmáx), temperaturas médias (Tméd) e temperaturas mínimas (Tmín) registradas na estufa de polietileno que continha o minijardim clonal de Eucalyptus benthamii $\times$ Eucalyptus dunnii, ao longo de 352 dias de coletas sucessivas de brotações.

TABLE 4: Pearson correlation matrix between the ministumps survival (SM), minicuttings production per square meter (PMQ), average maximum temperatures (Tmáx), average temperatures (Tméd) and minimum temperatures (Tmín) collected in the polyethylene greenhouse containing the clonal minigarden of Eucalyptus benthamii $\times$ Eucalyptus dunnii, in 352 days of minicuttings successive collections.

\begin{tabular}{lccccc}
\hline Característica & SM & PMQ & Tmáx & Tméd & Tmín \\
\hline SM & 1,000 & - & - & - & - \\
PMQ & $-0,022^{\text {ns }}$ & 1,000 & - & - & - \\
Tmáx & $-0,057^{\text {ns }}$ & $0,378^{* *}$ & 1,000 & - & - \\
Tméd & $-0,014^{\text {ns }}$ & $0,481^{* *}$ & $0,835^{* *}$ & 1,000 & - \\
Tmín & $0,023^{\text {ns }}$ & $0,451^{* *}$ & $0,510^{* *}$ & $0,899 * *$ & 1,000 \\
\hline
\end{tabular}

Em que: ${ }^{\text {ns }}=$ não significativo a $5 \%$ de probabilidade de erro, pelo teste $\mathrm{F} ; * *=$ significativo a $1 \%$ de probabilidade de erro, pelo teste $\mathrm{F}$. 
Wendling et al. (2003) observaram comportamento variável em função do clone, sendo que a produção oscilou de 2,0 a 9,7 miniestacas por minicepa, porém, sem apresentar uma tendência clara. Os autores sugeriram que esse comportamento pode estar associado à necessidade de adaptação inicial das minicepas ao sistema de hidroponia, bem como, a quebra de dominância apical após a poda. Portanto, após algumas coletas, as gemas dormentes tornaram-se reativas, resultando em maior estímulo ao crescimento, e melhor ajuste ao manejo do minijardim clonal com o decorrer das coletas.

\section{CONCLUSÕES}

As minicepas apresentaram elevado percentual de sobrevivência ao longo de 352 dias de coletas sucessivas de brotações, o que indicou elevada longevidade, sendo que a produção de miniestaca variou conforme o clone e mostrou-se muito sensível às estações do ano e às oscilações da temperatura. A maior produção de miniestacas por minicepa ocorreu nas estações mais quentes (primavera e verão), e a menor nas estações mais frias (outono e inverno).

\section{AGRADECIMENTOS}

À Embrapa Florestas, à Universidade Federal do Paraná e ao CNPq pelo suporte prestado.

\section{REFERÊNCIAS BIBLIOGRÁFICAS}

ALFENAS, A. C. et al. Clonagem e doenças do eucalipto. Viçosa: Ed. UFV, 2004. 442 p.

ALMEIDA, F. D. et al. Eficiência das auxinas (AIB e ANA) no enraizamento de miniestacas de clones de Eucalyptus cloeziana F. Muell. Revista Árvore, Viçosa, v. 31, n. 3, p. 455-463, 2007.

ASSIS, T. F.; MAFIA, R. G. Hibridação e clonagem. In: BORÉM, A. (Ed.). Biotecnologia florestal. Viçosa: Suprema Gráfica e Editora, 2007, p. 93-121.

BRONDANI, G. E. Miniestaquia e micropropagação de Eucalyptus benthamii Maiden \& Cambage x Eucalyptus dunnii Maiden. 2008. 188 f. Dissertação (Mestrado em Engenharia Florestal) - Universidade Federal do Paraná, 2008. CUNHA, A. C. M. C. M.; WENDLING, I.; SOUZA JUNIOR, L. Produtividade e sobrevivência de minicepas de Eucalyptus benthamii Maiden et Cambage em sistema de hidroponia e em tubete.
Ciência Florestal, Santa Maria, v. 15, n. 3, p. 307310, 2005.

CUNHA, A. C. M. C. M. da Relações do estado nutricional de minicepas e condições meteorológicas com o número e o enraizamento de miniestacas de eucalipto. 2006. 99 f. Dissertação (Mestrado em Ciência Florestal) Universidade Federal de Viçosa, 2006.

ELDRIDGE, K. et al. Mass vegetative propagation. In: ELDRIDGE, K. et al. Eucalypt domestication and breeding. Oxford: Clarendon Press, 1994, p. 228-246.

EMBRAPA. Empresa Brasileira de Pesquisa Agropecuária. Programa SOC - Software

Científico, Versão 2.1, Embrapa Informática Agropecuária, Campinas, 1990.

FERREIRA, E. M. et al. Determinação do tempo ótimo do enraizamento de miniestacas de clones de Eucalyptus spp. Revista Árvore, Viçosa, v. 28, n. 2, p. 183-187, 2004.

HARTMANN, H. T. et al. Plant propagation: principles and practices. $7^{\text {th }}$ ed. New Jersey: Prentice-Hall, 2002. 880 p.

HIGASHI, E. N. et al. Nutrição e adubação em minijardim clonal hidropônico de Eucalyptus. Instituto de Pesquisas e Estudos Florestais IPEF, 2002. 21 p. (Circular Técnica IPEF, 194). ROSA, L. S. Adubação nitrogenada e substratos na miniestaquia de Eucalyptus dunnii Maiden. 2006. 89 f. Dissertação (Mestrado em Engenharia Florestal)-Universidade Federal do Paraná, 2006.

SANTOS, A. P. et al. Efeito da estaquia, miniestaquia, microestaquia e micropropagação no desempenho silvicultural de clones de Eucalyptus grandis. Scientia Forestalis, Piracicaba, n. 68, p. 29-38, 2005.

SOUZA JUNIOR, L.; WENDLING, I. Propagação vegetativa de Eucalyptus dunnii via miniestaquia de material juvenil. Boletim de Pesquisa Florestal, Colombo, n. 46, p. 21-30, 2003.

SOUZA JUNIOR, L. et al. Miniestaquia de Grevillea robusta A. Cunn. a partir de propágulos juvenis. Ciência Florestal, Santa Maria, v. 18, n. 4, p. 455-460, 2008.

TITON, M. et al. Efeito do AIB no enraizamento de miniestacas e microestacas de clones de Eucalyptus grandis W. Hill ex Maiden. Revista Árvore, Viçosa, v. 27, n. 1, p. 1-7, 2003 a.

TITON, M. et al. Eficiência das minicepas e microcepas na produção de propágulos de clones de Eucalyptus grandis. Revista Árvore, Viçosa, v. 27, n. 5, p. 619-625, 2003b. 
WENDLING, I. Propagação clonal de híbridos de Eucalyptus spp. por miniestaquia. 1999. 70 p. Dissertação (Mestrado em Ciência Florestal)Universidade Federal de Viçosa, 1999.

WENDLING, I. et al. Efeito do regulador de crescimento AIB na propagação de clones de Eucalyptus spp. por miniestaquia. Revista Árvore, Viçosa, v. 24, n. 2, p. 187-192, 2000.

WENDLING, I.; XAVIER, A. Gradiente de maturação e rejuvenescimento aplicado em espécies florestais. Floresta e Ambiente, Rio de Janeiro, v. 8, n. 1, p. 187-194, 2001.

WENDLING, I.; XAVIER, A. Miniestaquia seriada no rejuvenescimento de clones de Eucalyptus. Pesquisa Agropecuária Brasileira, Brasília, v. 38, n. 4, p. 475-480, 2003.

WENDLING, I. et al. Influência da miniestaquia seriada no vigor de minicepas de clones de Eucalyptus grandis. Revista Árvore, Viçosa, v. 27, n. 5, p. 611-618, 2003.

WENDLING, I.; XAVIER, A. Influência da miniestaquia seriada no vigor radicular de clones de Eucalyptus grandis. Revista Árvore, Viçosa, v. 29, n. 5, p. 681-689, 2005.

XAVIER, A.; COMÉRIO, J. Microestaquia: uma maximização da micropropagação de Eucalyptus.

Revista Árvore, Viçosa, v. 20, n. 1, p. 9-16, 1996.

XAVIER, A.; WENDLING, I. Miniestaquia na clonagem de Eucalyptus. Viçosa: SIF, 1998. 10 p.

(Informativo Técnico SIF, 11) 